\title{
The Cyclical Integration Model as a Way of Managing Major Educational Change
}

\author{
Richard G. Berlach \\ The University of Notre Dame Australia, Fremantle 6959, Australia \\ Correspondence should be addressed to Richard G. Berlach, richard.berlach@nd.edu.au
}

Received 24 August 2010; Accepted 1 November 2010

Academic Editor: Phillip J. Belfiore

Copyright () 2011 Richard G. Berlach. This is an open access article distributed under the Creative Commons Attribution License, which permits unrestricted use, distribution, and reproduction in any medium, provided the original work is properly cited.

Where minds meet, there lies the change vector. With regard to change management, however, minds regularly fail to meet in the crucial change space. They either unwittingly zip past each other, deliberately avoid one another, or worse still, collide with excruciating impact. This paper examines the interrelated role of government, the public service and professionals in successfully transitioning major change initiatives. It is argued that unless these agencies operate in synchrony, change negotiation is likely to be hampered. To this end, a model of "Cyclical Integration" is presented and supported by driving questions for each of the three agencies facilitating the change process. Although it is considered that these questions are sufficiently broad to encompass change management across any number of enterprises, what is being considered in this paper is the arena of compulsory education.

\section{The Challenge}

According to respected change management theorist Michael Fullan [1], not too many people relish the thought of change. With a touch of irony, Fullan suggests that "if people were given the literal choice of "change or die" ..." (p. 42), societal evidence suggests that the likelihood of choosing change is nine to one against them. Change is difficult, it always has been. Several thousand years ago, Stoic philosopher and Roman emperor Marcus Aurelius [2] wrote, "We shrink from change; yet is there anything that can come into being without it?" (p. 108). Marris [3] agrees that humans find change distasteful, suggesting that we do so as we fear the loss, stress and struggle that change forces upon us. Yet, can anything indeed "come into being without it"? Those of us who have experienced the passage of time between the advent of television and twitter, for example, would be forced to answer in the negative, knowing that communication has become better, faster, cheaper, and more reliable as society has moved from valve to digital to optic fibre to nanotechnology. Such change is usually touted as being desirable as it is associated with evolutionary progress. Given society's proclivity for endorsing this forward momentum theory of human history, the aphorism "the only thing that will never change is change itself", may be truer than we think. So, if change is inevitable, and it would appear that it is, then it would follow that the better change is managed, the less traumatic are likely to be its effects.

Fullan's [1] grim view of change, as cited above, is unlikely to come as a revelation to those who have been involved in the enterprise of managing educational change for any extended period. Whenever change is mooted, securing universal agreement regarding its necessity is rare. Rarer still is obtaining agreement regarding its nature, extent, timing, and resourcing. What is not rare, however, is resistance, often encountered in the form of direct attack, passive-aggressive posturing, or begrudging acquiescence. What causes such resistance? The language of behaviourism may be helpful in attempting to answer this question. Put simply, change is an organism's response to a given stimulus. And here is the rub, for a change stimulus in education usually comes in the form of an edict from a superordinate (leader) through the conduit of a subordinate (manager) on to a field worker (implementer). This is a hierarchical process and one which invariably draws the question "why?" from grass-roots implementers: why should I do something I have not been consulted about? Why should I do something I do not philosophically believe in? Why should I do 
something that ivory-tower politicians and bureaucrats see as being revolutionary and I see as being just plain dumb and unworkable? Put simply, a disconnect is often created between the stimulus and the response, making change problematic.

Half a century of research in motivational theory [4, 5] has verified that behavioural change comes in one of two ways, as a response to a stimulus presented in either the external or internal environment. Response to an externally mediated stimulus normally results in extrinsically motivated behaviour in the form of compliance, whereas an internally generated stimulus results in intrinsic motivation in the form of desire. It has been shown that both forms of motivation are powerful and highly efficacious for human endeavour $[6,7]$. It is the intrinsic form of motivation, however, that tends to be the more enduring as it is more closely aligned with personal goals [8-10]. Essentially, change from within the individual (self-motivated) is less stressful, more highly motivating and more enduring than change which is externally mediated. In Rotter's [11] terms, if the locus of control is internal, change is likely to succeed for, in the language of deCharms $[12,13]$ the driver sees him/herself as the origin rather than the pawn in the transaction. Given such an understanding, externally imposed change is likely to be a potentially unpalatable motivator, more so if it is hierarchically imposed.

Hierarchy suggests distance. As such, the further individuals are from the source of a change decision, the greater will be their psychological alienation and associated angst $[14,15]$. Education is not immune from this general principle. Decisions are typically generated by government, regulated by the public service and implemented by teachers. This top-down model is represented in Figure 1. Although informed communication between these stakeholders is often attempted via focus groups, committee representation, individual and group submissions, and the like, there is normally little continuing effectual dialogue once each agency has attended to its designated task. Decisions are made, policy is drafted and consequent implementation expected.

Such a top-down model typically begins to fracture as decisions are moved further and further down line, as people lose sight of origins and begin to feel like pawns. The reasons for potential hierarchical fragmentation are perhaps selfevident. Nevertheless, key factors are worth highlighting. In the first place, politicians are by definition political creatures-they play the public image game necessary for holding government at the next election. They have a confident approach, are full of optimism, and use the sort of (often illusionary) jargon that tends to suggest they know what they are talking about and really do have the answers. By way of example, we can quote verbatim the inspirational language peppered throughout a recent speech to Teaching Australia given by the then Australian Federal Minister for Education:

committed to improving ... improvement in quality ... collaborative reform ... new era of quality and reform ... share responsibility for

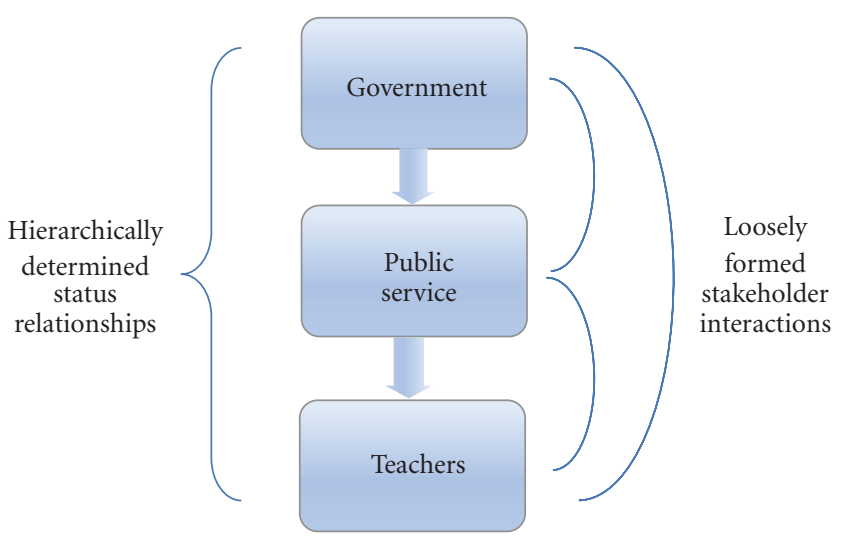

FIGURE 1: Change agent relationship: hierarchically based model.

educational outcomes ... teacher quality ... raise achievement in disadvantaged school communities ... Improving our schools ... higher impact and performance ... rigorous shared evaluation ... for every child, in every school, in every community ... Education Revolution ... transparency and openness ... better education system [16].

Inspirational stuff, and all this promise in a single speech. But our purpose here is not to criticise, far from it, the Minister is doing precisely what politicians are groomed to do, namely, paint and sell the big picture of government. What needs to be realised is that once the "Education Revolution" has been motivated in this fashion, the then Minister was required to attend to her other duties as Minister for Employment and Workplace Relations, Minister for Social Inclusion, and Deputy Prime Minister. Given the Minister's competing portfolios, a big picture policy proclamation is possibly all that can be humanly managed. She delivers the essential message and then relies on the public service to develop an implementation strategy.

Unlike politicians who make pronouncements, public servants are expected to administer the process of turning a ministerial statement into implementable policy. This is an unenviable task, for it is invariably the public service (department) that will be the proverbial meat in the sandwichpoliticians pushing down (deadlines, budgets, and accountability) and teachers and their professional associations pushing up (policy criticism, workload, and remuneration issues). There is also the frustration of drafting and redrafting policy ad nauseam, until a compromise is reached between government and stakeholders. Further, there is the matter of often being required to "implement poor policy geared to short-term political expediency-and where the longerterm consequences were not fully contemplated or analysed" [17] (p. 341). Finally, there is the frustration of having to deal with continual change often for the sake of change as governments change, so that the incoming government can assert its imprimatur. Wanna [17] reported that at around table conference delegates lamented that departments were no longer able to "know "the minister's mind" and this could 
become difficult when ministers changed frequently (one executive had worked for 33 different ministers in their career to date)" (p. 342).

Given the nature of the interplay between politics and the public service, hierarchical fragmentation may not be an unreasonable expectation. Bourgon's [18] representation of this interplay details the intricacies of the decision making process (Figure 2). The diagram shows that although the work of the two bodies intersects in the middle of the "Figure eight", each by-and-large operates in its individual world. Policy so produced is then presented to teachers for implementation.

It is often at this point of "now do it", such as in the case of the outcomes-based education scenario that has recently plagued Western Australian education $[19,20]$, that a grass-roots outcry erupts. Research literature suggests that it is not unusual for teachers to feel "dumped upon from on high", when encountering implementation directives for which they feel no ownership [21-26]. Perhaps the bluntest assessment of a hierarchically managed bureaucracy, written in the British context, comes from the pen of Minogue [27]:

Few people doubt that the quality of education in Britain's schools has degenerated and that it has done so in almost exact proportion to the involvement of the Department of Education in telling teachers what they must do. The more directives, the more bureaucracy endured, the worse the results (para. 3).

Fragmentation en route from idea to policy to implementation has the potential of torpedoing any initiative. Success at the point of delivery is always the best indicator of an effectively managed change process. Bourgon [18] is insightful when she writes:

A good public policy is one that achieves the intended results at the lowest possible cost to society while minimising unintended consequences. While policy decisions receive most attention, policy implementation is where success is defined. This is where we can see the difference between grand ideas with no future and good ideas that generate long term benefits for the country (p. 394, italics added).

Given that the hierarchically based model has the potential to suffer from downline fragmentation, change management based on a more stable foundation may yield better results. The alternative presented here is the Cyclical Integration Model (Figure 3). Following Fullan's [1] lead that modern theories of change management lead "inevitably to the conclusion that working on "coherence" is the key to dealing with the fragmented demands of overloaded reform agendas" (p. xii), the model as presented acknowledges the unique contributions of the three stakeholders under consideration-government, the public service, teacherswhile at the same time attempting to strengthen the relationships between them. How this is undertaken, together with an investigation of the role of the Integrator, is now considered.

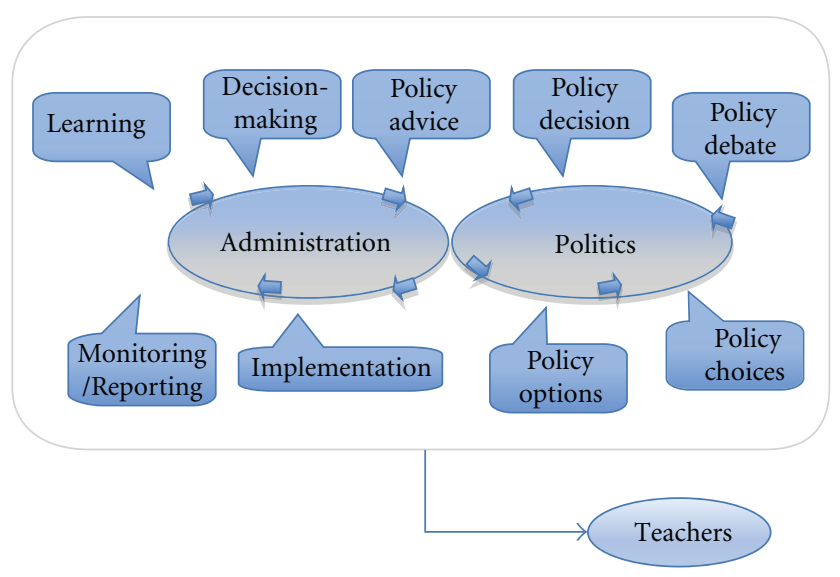

Figure 2: Bourgon's [18] (p. 395) interplay between administration and politics (Model embellished with a loop to Teachers).

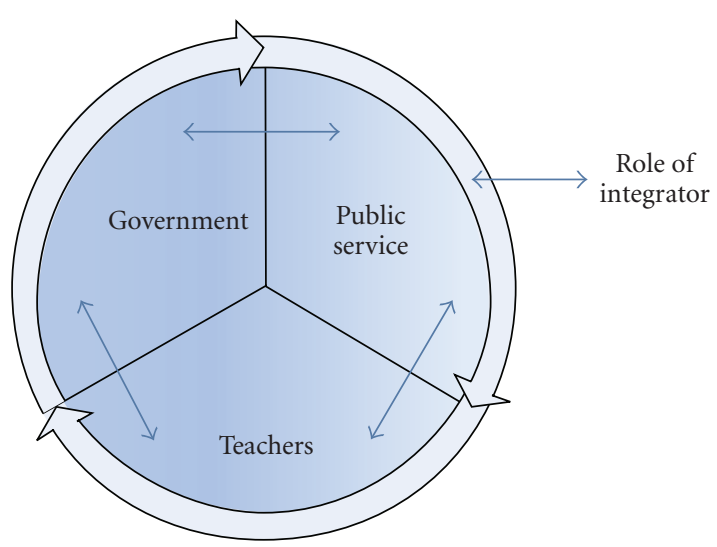

FIGURE 3: Change agent relationship: cyclical integration model.

\section{The Cyclical Integration Model of Change Management}

The model presented in Figure 3 is comprised of an integrated operational component (government, public service and teachers as encountered earlier) and one external Integrator having an executive function. The operational component is created to deal with introduction of significant change initiatives. We will return to the notion of what may be termed as significant later. More immediately, the discussion revolves around the function of the operational component and then moves to a consideration of the role of the integrator.

The model is organic in nature in that rather than operate in a push-down fashion, members of the operational component are engaged in collegial dialogue during the formulation of a proposed change. Government still sets agendas, the public service still produces policy documents which teachers still implement, but each does so in an environment of ongoing dialogue and mutual cooperation (Figure 3, arrows). Each party's representatives sit together at the discussion table armed with what I have termed 
"framing questions" rather than with predetermined objections, premature solutions, or prepared ideologies.

The framing questions are big picture in nature. Although change management theorists such as Michael Fullan and Andy Hargreaves have repeatedly advocated for such drivers as key in any change process, they are often the very questions that are not considered in any hierarchically based model of change management $[28,29]$. Nixon [30] suggested that this is because hierarchy is based in comfortable control and power. He insists that members of the ruling oligarchy conveniently live by "the assumption that people are simple and simple people need simple tasks. The simple tasks provide for better measurement and therefore better control" (para 2). Regardless of whether or not such a "simpleton thesis" can be sustained, hierarchical management is clearly about rulers and the ruled. Under such a regime, if it happens at all, change is likely to occur via the fiat of authority or through acquiescence brought about by exhaustion, rather than through enthusiastic participation in a coordinated process. Unfortunately, avoidance of external punishment, rather than the generation of internal satisfaction, becomes the prime motivator for change.

The kind of change management being advocated in this paper is premised on consensus rather than dictum. Framing questions for guiding the process have been developed for each of the key stakeholders (Tables 1, 2, and $3)$. These are not exhaustive but more illustrative of the kinds of questions that need to be considered when major change is being contemplated. Attention to the matters raised in the framing questions may go a long way to helping alleviate the angst often associated with change. It may also lead to fewer ineffectual policy decisions and concomitant implementation failures occurring (such as Western Australia's ill-conceived foray into outcomes-based education and the recent federal government policy of distributing laptops to secondary students without giving preliminary thought to matters such as hardware sourcing problems, hardware storage, technical support, and software updates).

The framing questions for government (Table 1) focus on big picture issues, while at the same time recognising the importance of national priorities and international trends. Considered answers to questions such as these is likely to result in establishing greater jurisdictional respectability, and providing a clearer project rationale, leading to a more satisfactory outcome.

Whereas the government framing questions are change policy related, public service questions (Table 2) focus more on the change process. Giving serious attention to such questions is likely to result in a better coordinated approach, fewer resolutions later proving to be unworkable, and greater receptivity by teachers.

The framing questions for the teaching profession (Table 3) centre on implementation imperatives. At the heart of these questions is an overarching question which asks "what could possibly hamper policy delivery?". In the ultimate sense, as identified earlier in this paper [18], policy without successful delivery is ineffective, frustrating and for many individuals, psychologically and emotionally costly.
TABLE 1: Framing questions for government as an agent of change.

\section{Enterprise focus}

Does a clear understanding exist of precisely what is meant by the term "compulsory education"? If not, why not; if yes, how does the proposed change fall within defined parameters?

International respectability

Does the proposed change model have any international pedigree? Are countries who are performing strongly on measures such as TIMMS $^{1}$ and PISA $^{2}$ adopting/considering similar changes?

\section{Driving agency}

What hard evidence is there that this change ought to be considered? If little, should a report be commissioned? If so, how will objective committee representation be guaranteed?

Budgetary possibility

Is a report being commissioned to buy political time or is funding available to implement report recommendations?

\section{Clarity of Purpose}

Is the primary aim of the change to gain political leverage or to secure real, beneficial and lasting educational advantage?

\section{Public service achievability}

Given other tasks currently being undertaken, are sufficiently experienced personnel available in the relevant government department to do "due diligence" to this task at this time? If not, how will the issue of required personnel be addressed?

Change evaluation

How will "bang for the buck" be evaluated? How will it be determined whether or not tax payers' money has been appropriately invested?

\section{Integrator profiling}

Given the expertise on both sides of the House, who is in the best position to take on the role of Integrator for this particular project?

\footnotetext{
${ }^{1}$ Trends in International Mathematics and Science Study.

${ }^{2}$ Programme for International Student Assessment.
}

Although all three groups are asking different questions, what unites them is their corporate desire to achieve a successful outcome. In considering a proposed curriculum change, for example, the government representative would raise matters of international importance vis-à-vis local desirability (the "why" question); the public service representative would raise issues relating to resource availability (human and budgetary) to manage the change (the "what with" question); and the teacher representative might want to consider professional development and content transition issues (the "how" question). It is only when all of these matters are considered and catered for that the proposed change has any chance of being effectively implemented.

The framing questions address the big issues and are undergirded by four assumptions. The first is that each member of the operational component has a genuine desire to put children's educational needs ahead of their own professional posturing. A cynic might say that such an assumption immediately sounds the model's death knell as politicisation is in everything. I prefer to take more of an optimistic view, namely, that with something as important 
as the education of a nation's children, individuals can work successfully together, if they are committed to doing so. The second assumption is that ongoing dialogue in a spirit of collegiality produces greater internal motivation leading to results superior to those obtainable by forced compliance. A third assumption is that the earlier in the process that participation occurs, the greater will be the sense of ownership, thus providing greater, and more immediate opportunity to experience the intrinsic reinforcement spoken of earlier. With personal ownership taking a higher profile, resistance to change is likely to be reduced and with it problem-solving effectiveness increased.

The final assumption is that all members of the operational component accept accolades for success and responsibility for failure, as a unit. In other words, no one plays the "blame game"- the unit either succeeds or fails as one body. Such an assumption acts as a powerful success motivator. Teachers would find it more difficult criticising politicians for not listening, the public service would be less likely to complain about the lack of available resources for task completion, and governments would be less inclined to accuse teachers of thwarting the reform agenda. It is these assumptions together that facilitate the model's integrative orientation.

The proposed model necessitates risk-taking on the part of all parties-the risk of accepting the underlying assumptions; the risk of surrendering the power that comes with status; the risk of having to accept compromise; the risk of operational component failure despite the genuine efforts of all parties. The reward, however, may justify the risk, for seeing a project through to successful conclusion is likely to produce great satisfaction for members of the operational component. Leaders need to take calculated risks, with success then taking the fear out of the next risk. Psychologist Edward Thorndike [32] realised this fact some one hundred years ago when he proposed the Law of Effect, namely, that people are more likely to repeat responses that have satisfying effects. Importantly, risks are worthwhile if taking them is likely to result in more favourable outcomes for end users, namely, students.

In a significant-in terms of size and scope-metaanalytic study relating to learning undertaken by Leithwood et al. [33], it was found that successful leaders displayed three sets of core practices: setting directions, defined as providing clarity of purpose; developing people, defined as creating shared ownership regarding the direction to be taken; redesigning the organisation, defined as delivering change which makes something obviously better. The model being advocated here allows for all three core practices to be engaged.

A second platform of the proposed model is the function of an Integrator (Figure 3) and this will now be considered. Beginning with what the Integrator is not, $s / h e$ is not a regulator, moderator, arbitrator, information disseminator or in any sense an active participant in the operational component's formal deliberations. In fact, the Integrator need not even attend any of the component's meetings, however, must of necessity be on top of the general matters under consideration. This individual's role is one of consulting,
TABLE 2: Framing questions for the public service as an agent of change.

\section{Theoretical justifiability}

What theory with an established track record is being used to interpret the proposed change? What proposed model is being considered?

\section{Conceptual coherence}

How is the change being conceived of in terms of resourcing, responsibilities, professional development and implementation timelines?

\section{Structural integrity}

In line with developmental learning theories, is content sequenced and incremental in presentation? Is the proposed change so structured that its various components sequenced and integrated?

\section{Linguistic clarity}

Can the proposed change be understood in "plain language"? Is it free of jargon, spin and embellishment? Is it accessible to the general public?

Psychometric validity

Are evaluation regimes easily comprehendible or does one have to hold a PhD in statistical analysis to understand how children are being assessed?

\section{Empirical veracity}

Prior to being adopted for system-wide implementation, have field trials shown the proposed change to be efficacious?

\section{Courageous humility}

If field-failure is evident, is there a preparedness to go back to the drawing board rather than press on regardless?

after a scheduled meeting, with parties who have indicated that they would appreciate an independent and objective view on anything that may have transpired during the course of the meeting. The arrow heads on the outside circle of the model (Figure 3) represent the fluid environment in which the Integrator operates. S/he is available to all parties but is not aligned with any.

The Integrator listens to concerns and after due deliberation (possibly following discussion with other members of the operational component), proposes a way forward. $\mathrm{S} /$ he may be able to provide a different perspective on a particular impasse or stalemate that the group as a whole has encountered. In a sense, the Integrator is akin to a counsellor, a sounding board. S/he attempts to consolidate available information on an issue and from that integrative perspective present novel, different, and creative ways of moving forward. It is important to reiterate that the Integrator is not part of the decision-making process but acts as an independent consultant advisor. Once the advice has been provided, the bona fide members of the operational component meet to discuss the insights that have been provided and to determine a way forward. Such a "guide on the side" - an individual with vast experience but without authority-is likely to be viewed positively by those who have been charged with making the tough decisions.

Tice [34] speaks of scotomas, or blind spots, which prevent people from seeing things because of a perceptual 
fixedness. Like the rest of us, politicians, public servants, and teachers, irrespective of good intentions, can be hampered by scotomas. The Integrator, who is not as invested in the outcome as the major players, may be in a better position to draw attention to previously unobserved phenomena.

Who should fulfil the role of Integrator in the present model? The recommendation is that a politically uncompromised and respected member of society be assigned the role of Integrator. An individual such as an academic, company CEO, court judge, or senior health care professional would fit the bill admirably. The appointment would need to be made in a bipartisan fashion, thereby discouraging either side of the house from crying foul at some later date. There are a number of reasons why respected individuals from the broader community would fill this role. The first relates to the apolitical status of the appointee, namely, someone who works with government but stands outside its influences on the matters under consideration. Having an individual assisting governments to recognise their own scotomas is useful, for as Fullan [1] concludes:

If we are to achieve large-scale reform, governments are essential. They have the potential to be a major force for transformation. The historical evidence to date, however, suggests that few governments have gotten this right (p. 236).

In the present model lies an opportunity for governments, and future governments, to make a difference, to be tours de force for transformation.

Secondly, a politically uncompromised Integrator from the broader community has a greater chance of being seen by all parties as an apolitical appointment. Thirdly, being nonaligned, such an individual is less likely to be intimidated by the government representative of the operational component. Fourthly, individuals from the recommended sectors have the requisite experience as they sit on and chair numerous committees on a regular basis. Finally, there is a strong likelihood that they will still be around after the next election, regardless of which party forms government, thereby providing continuity of process.

It is not difficult to anticipate objections to the proposed model. The first may be that governments are elected to govern and not to manage. Two retorts are appropriate here. In the first place, a managerial function for government is not envisaged under the proposed model. Participation is at the level of policy development. In the second place, governments all too often appeal to "a clear mandate" for introducing unpopular policies. In a democracy, winning an election is in fact not carte blanche authorisation for introducing whatever a government wishes to under the guise of a "mandate". The model ensures that governments remain openly accountable for, in a hands-on fashion, the introduction of significant policy initiatives.

The term "significant change" attempts to counter the second potential objection to the proposed model, namely, that relating to ministerial workload. This can be addressed by clarifying where a Minister's direct input would be required. To begin with, policies may be seen as being either internal or external to a prevailing organisational
TABLE 3: Framing questions for teachers (and their professional associations) as agents of change.

\section{Industry support}

Do the arms of the profession potentially affected by the change see it as being desirable and generally advantageous?

Professional integrity

How does the proposed change generally align with the nature of "teachers' work" [31]?

Workload reality

How much extra time will teachers be required to give to implementing the proposed change? What will be the overall impact on workloads?

\section{Curriculum viability}

Will the proposed change impact further on the crowding of the curriculum? Is it a replacement for something or an addition?

\section{Pedagogical integrity}

Are teaching methods expected to change as a result of the initiative? If so, have the proposed methods been tested?

Provision of Professional Development

What and how many PD events will be required to resource teachers prior to the change being implemented?

\section{Practicability feasibility}

Given the nature of the school year, is the change achievable within the timeframe proposed?

\section{Transition arrangements}

How will students be transitioned so that their learning will not be negatively affected by the change?

\section{Parental acceptance}

Are parents likely to see this change as positive and have they been provided with sufficient information to make such a judgement?

system. Internal policies are those which provide a revision to existing structures with no Cyclical Integration process being required. Policies external to a current system of organisation, on the other hand, where significant structural and resource change is required, would benefit by being subjected to the integrative process of the model. This is where ministerial input would be required. Examples of policies external to the system might be curriculum reform; pedagogical innovation; introduction of new technologies; or major changes in school campus design.

A final objection may be that simply because government, senior public servants, and teacher representatives may agree on a change initiative, that does not mean that the rank-and-file will be adequately informed. This is of course true, but may be alleviated by creating a website posting minutes of the operational component's meetings. Concerns can then be aired online and addressed at the next meeting. Latterly, governments have been keen on the use of the epithet "open and transparent" when making policy announcements. Given this predisposition, it would be difficult to see why a government would object to informing the teaching profession of what transpired at operational component meetings. 
It is accepted that even at the end of the process not all parties may be satisfied. Some wit once remarked that if six people were asked to debate a topic they would generate seven opinions. That may be human nature. Nevertheless, under the model, all significant stakeholders have been represented; all stakeholder representatives have talked with each other at the same time; all are committed to executing an agreed upon policy initiative in the most change-friendly way possible; all constituents have been duly advised of proposed changes and their responses considered. Such a process has the chance of generating a win for both policy and people, albeit predictably, not for every individual.

\section{Epilogue}

If change management was to be approached differently, it is likely that outcomes too would be different. I wonder how many more people need to be lost to the profession as a result of suffering at the hands of what they perceive to be ineffective change management protocols? This is a significant question, as evidence exists showing that the profession is haemorrhaging teachers. A national report titled Top of the Class [35] cited statistics which indicated that it is

... estimated that up to $25 \%$ of teachers may leave the profession within five years. In the recent survey of beginning teachers by the Australian Education Union, $45.6 \%$ of respondents did not see themselves teaching in 10 years time (p. 9).

State projections are even more dire. In Western Australia, for example, the Department of Education and Training [36], reported that it "loses up to 35\% of beginning teachers in the first two years of employment and up to $50 \%$ within five years" (p. 12). In economic terms alone, this is a disaster given that it takes a minimum of four years to train a teacher and within five years almost half of them have departed. The same department admitted in 2008 [37] that "the filling of public school vacancies has become relatively more difficult in recent years ..." (p. 5). Why are teachers leaving? There are undoubtedly many factors but what has been argued here is that a fundamentally flawed change management model ought not to be discounted as an explanation of teacher leakage.

Ramsey [38] identified 21 "significant national and New South Wales reports on teacher education" (p. 258) between the years 1980-1999. Since that time, a dozen or so nationally significant reports have also appeared. Intriguingly, few of these reports have dealt in any comprehensive fashion with the need for reconsidering the fundamentals of change management, that is, with the need to look at the relationship between government, the public service and the teacher, as being the major impediment to workforce satisfaction.

The Cyclical Integration Model of change management presents an opportunity for major stakeholders to formulate ideas in a collegial environment with the counsel of an experienced but operationally uninvolved community member. It provides an opportunity for doing things differently.
Bourgon [18], President Emeritus at the Canada School of Public Service, whose insights have been cited earlier, is adamant that a fresh perspective on change management is required. She writes:

These days, the hierarchical model of government increasingly co-exists with the management of networks. Modern government entails the management of the traditional power structure and of nonhierarchical, nontraditional relationships (p. 396).

Perhaps now is an opportune time to take a closer look at models which favour "nonhierarchical, nontraditional relationships". Perhaps this could result in change being managed in a way that is more palatable to those affected downline, namely, our change-damaged teachers.

\section{References}

[1] M. Fullan, The New Meaning of Educational Change, Routledge, New York, NY, USA, 4th edition, 2007.

[2] M. Aurelius, Meditations, Penguin Classics, 1964, 167.

[3] P. Marris, Loss and Change, Anchor Press, New York, NY, USA, 1975.

[4] B. Weiner, "History of Motivational Research in Education," Journal of Educational Psychology, vol. 82, no. 4, pp. 616-622, 1990.

[5] W. Huitt, Motivation to learn: An overview, Educational Psychology Interactive, Valdosta State University, Valdosta, Ga, USA, 2001, http://www.edpsycinteractive.org/topics/motivation/motivate.html.

[6] A. Bandura, Social Foundations of Thought and Action: A Social-Cognitive Theory, Prentice-Hall, Englewood Cliffs, NJ, USA, 1986.

[7] K. Barry and L. King, Beginning Teaching and Beyond, Social Science Press, Katoomba, Australia, 3rd edition, 1998.

[8] E. Deci and R. Ryan, Intrinsic Motivation and SelfDetermination in Human Behaviour, Plenum, New York, NY, USA, 1985.

[9] D. Schunk, "Inherent details of self-regulated learning include student perceptions," Educational Psychologist, vol. 30, pp. 213-216, 1995.

[10] D. Schunk and B. Zimmerman, "Self-regulation and learning," in Handbook of Psychology, Educational Psycholog, W.M. Reynolds and G.E. Miller, Eds., vol. 7, pp. 59-78, John Wiley \& Sons, Hoboken, NJ, USA, 2003.

[11] J. Rotter, Social Learning and Clinical Psychology, PrenticeHall, Englewood Cliffs, NJ, USA, 1954.

[12] R. deCharms, "Personal causation training in the schools," Journal of Applied Social Psychology, vol. 2, pp. 95-113, 1972.

[13] R. deCharms, "Motivation enhancement in educational settings," in Research on Motivation in Education, Volume 1: Student Motivation, R. Ames and C. Ames, Eds., Academic Press, Orlando, Fla, USA, 1984.

[14] A. Hargreaves, "The emotions of teaching and educational change," in International Handbook of Educational Change, Part 1, Section 2, A. Hargreaves, A. Lieberman, M. Fullan, and D. Hopkins, Eds., pp. 558-570, Springer, London, UK, 1998.

[15] S. Rosenholtz, Teachers' Workplace: The Social Organisation of Schools, Longman, New York, NY, USA, 1989. 
[16] J. Gillard, "Speech delivered to Teaching Australia," October 2008, http://mediacentre.dewr.gov.au/mediacentre/ Releases/AddresstotheTeachingAustraliaandBCASymposium .htm

[17] J. Wanna, "Independence and responsiveness-re-tying the gordian knot: IPAA roundtable," Australian Journal of Public Administration, vol. 67, no. 3, pp. 340-344, 2008.

[18] J. Bourgon, "The future of public service: a search for a new balance," Australian Journal of Public Administration, vol. 67, no. 4, pp. 390-404, 2008.

[19] R.G. Berlach, "Outcomes-based education \& the death of knowledge," in Proceedings of the Australian Association for Research in Education Conference, The University of Melbourne, Victoria, Australia, December 2004, http://www.aare .edu.au/04pap/ber04768.pdf.

[20] R. G. Berlach and M. O’Neill, “Western Australia's 'English' course of study: To OBE or not to OBE, perhaps that is the question," Australian Journal of Education, vol. 52, no. 1, pp. 49-62, 2008.

[21] S. Conley and N. S. Glasman, "Fear, the school organization, and teacher evaluation," Educational Policy, vol. 22, no. 1, pp. 63-85, 2008.

[22] C. Day and L. Smethem, "The effects of reform: Have teachers really lost their sense of professionalism?" Journal of Educational Change, vol. 10, no. 2-3, pp. 141-157, 2009.

[23] M. Fullan, Change Forces: Probing the Depths of Educational Reform, Farmer, London, UK, 1993.

[24] M. Fullan, Leading in a Culture of Change, Jossey-Bass, San Francisco, Calif, USA, 2001.

[25] A. Hargreaves and D. Fink, Sustainable Leadership, JosseyBass, San Francisco, Calif, USA, 2006.

[26] S. Horsley, "The politics of public accountability: implications for centralized music education policy development and implementation," Arts Education Policy Review, vol. 110, no. 4, pp. 6-13, 2009.

[27] K. Minogue, "The kids are Not Alright," The First Post, http://www.thefirstpost.co.uk/8084,opinion, politicians-notteachers-are-to-blame-for-britains-decline-in-education.

[28] J. Kotter, Leading Change, Harvard Business School, Boston, Mass, USA, 1996.

[29] J. Ryan and C. Rottmann, "Struggling for democracy: Administrative communication in a diverse school context," Educational Management Administration and Leadership, vol. 37, no. 4, pp. 473-496, 2009.

[30] K. Nixon, "Hierarchical Management Outdated," 1997, http:// www.bizjournals.com/triangle/stories/1997/05/05/smallb3 .html.

[31] R. Connell, Teachers' Work, Allen \& Unwin, Sydney, Australia, 1985.

[32] E. Thorndike, Educational Psychology: The Psychology of Learning, Teachers College Press, New York, NY, USA, 1913.

[33] K. Leithwood, K. Louis, S. Anderson, and K. Wahlstrom, How Leadership Influences Student Learning, Wallace Foundation, New York, NY, USA, 2004.

[34] L. Tice, Investment in Excellence, The Pacific Institute, Perth, Australia, 1990, audio recordings.

[35] House of Representatives, Standing Committee on Education and Vocational Training, Top of the Class: Report on the Inquiry into Teacher Education, House of Representatives Publishing Unit, Canberra, Australia, 2007.

[36] Department of Education and Training, "Workforce profile," Western Australia, Australia, 2006.

[37] Department of Education and Training, "WA teacher demand and supply projections," Western Australia, Australia, 2008.
[38] G. Ramsey, "Quality matters. Revitalising teaching: critical times, critical choices," Report of the Review of Teacher Education, New SouthWales, Australia, 2000. 


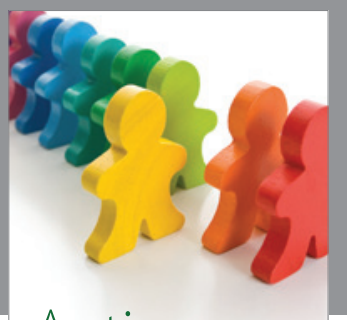

Autism

Research and Treatment
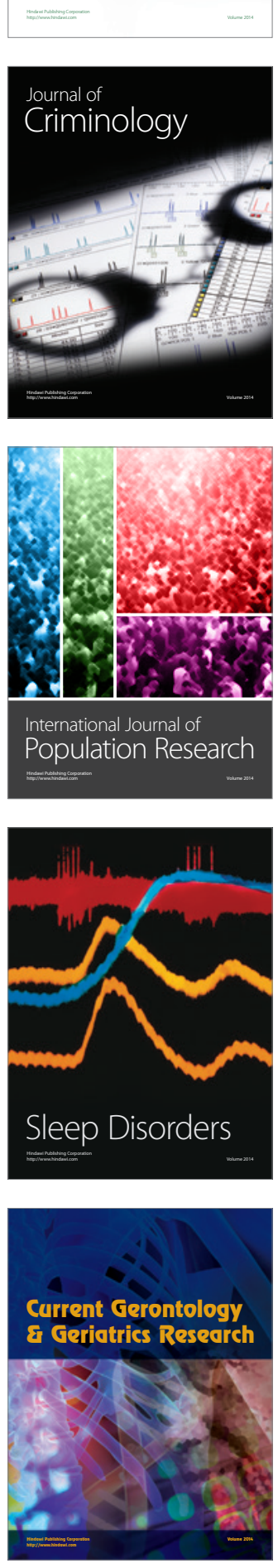
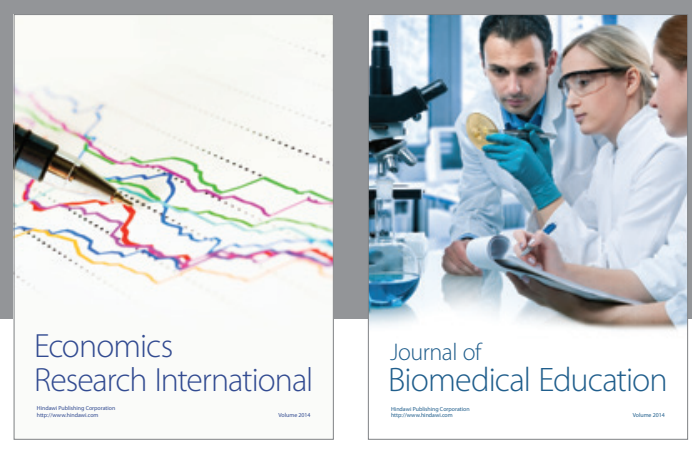

Journal of

Biomedical Education

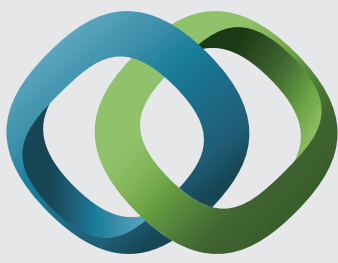

\section{Hindawi}

Submit your manuscripts at

http://www.hindawi.com
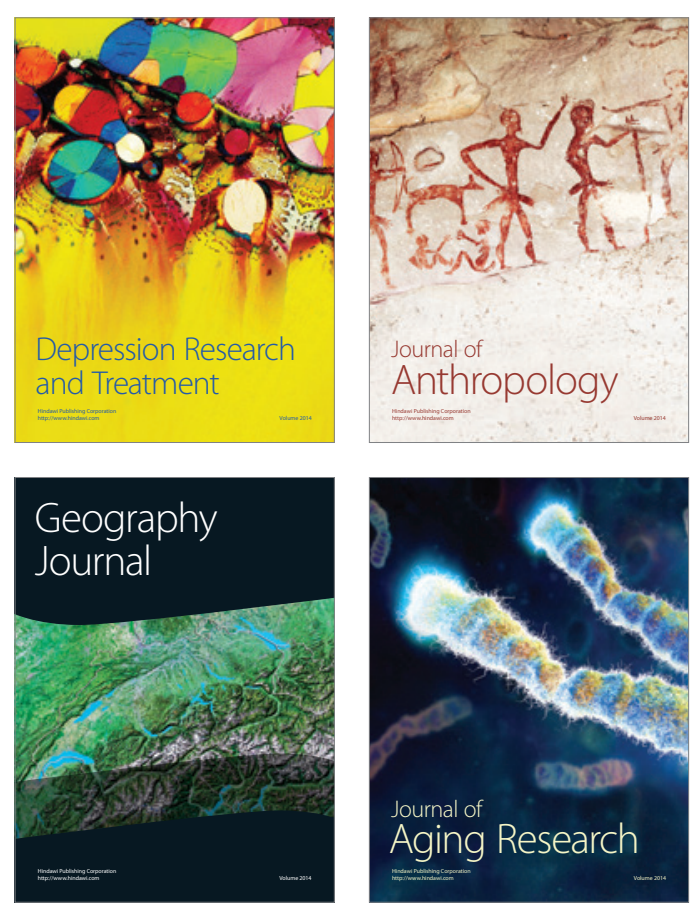

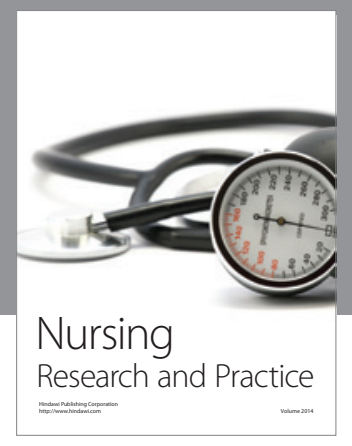

Nursing

Research and Practice

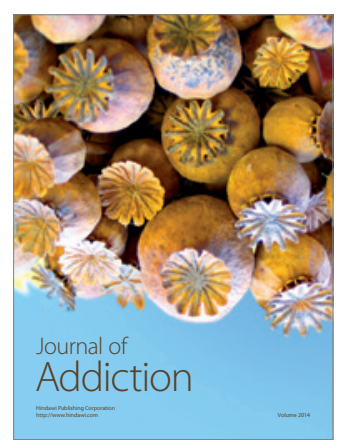

Child Development

Research

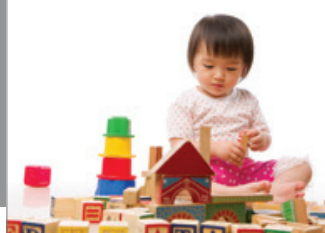

迥
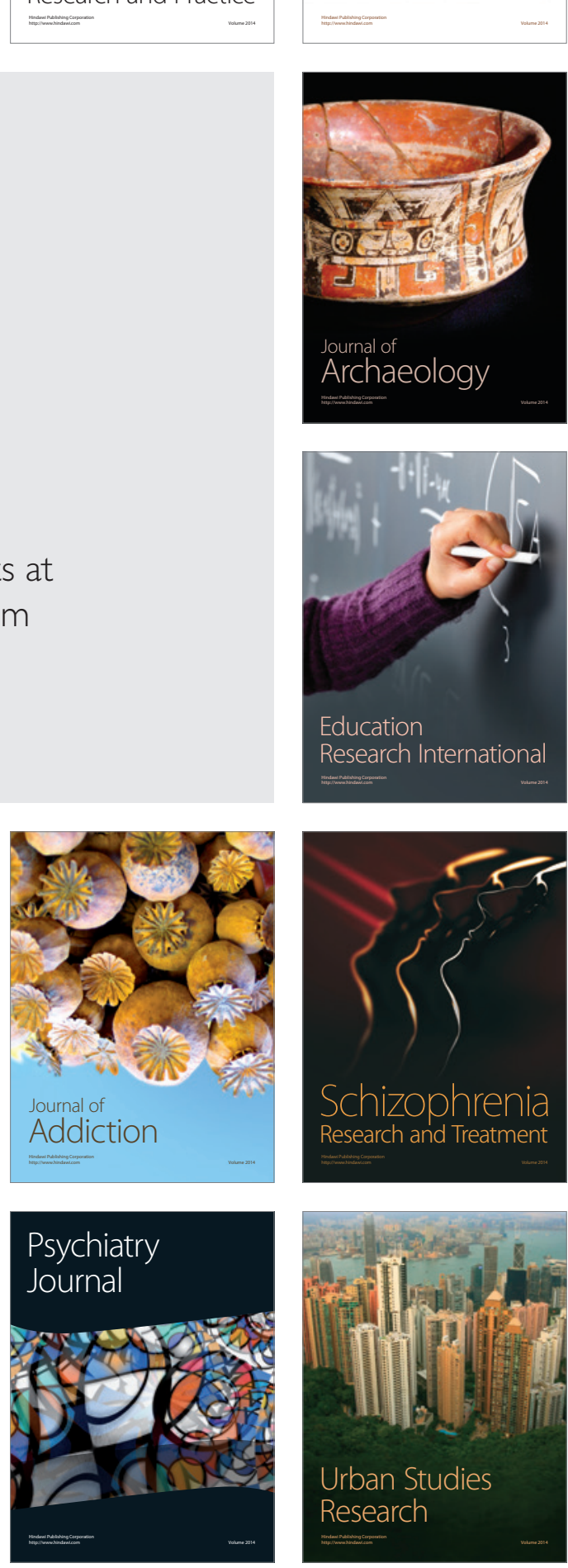